\title{
ATTIVITÀ NEUTRALIZZANTE IN VITRO \\ DI UN ESTRATTO DI ACIDO CICORICO NEI CONFRONTI DI HERPES SIMPLEX VIRUS TIPO I
}

Chisu L.', Borgna R.', Innocenti M.', Saddi M.',

Giaccherini C. ${ }^{2}$, Cabitza D.', Maccioni D. ${ }^{a}$,Vincieri F.F. ${ }^{2}$, Mulinacci N. ${ }^{2}$, De Logu A.'

'Dipartimento di Scienze e tecnologie Biomediche,

Sezione di Microbiologia Medica,

Università di Cagliari, Viale Sant'Ignazio 38, 09123 Cagliari

${ }^{2}$ Dipartimento di Scienze Farmaceutiche,

via Ugo Shiff 6, 50019 Sesto Fiorentino, Firenze

Nonostante gli herpesvirus, siano generalmente associati a malattie benigne, negli individui immunocompromessi si rendono spesso responsabili di patologie caratterizzate da elevata mortalità e morbilità.

L'avvento di farmaci anti-erpetici come l'aciclovir, ha migliorato la prognosi dell'infezione da herpes simplex.

Tuttavia, essi sono in grado di ridurre le manifestazioni cliniche dell'infezione primaria solamente quando vengono somministrati nelle prime fasi della malattia. Inoltre nessun farmaco è in grado di eliminare l'infezione latente. HSV è in grado di sviluppare resistenza all'aciclovir. Risulta quindi necessario individuare nuove molecole in grado di proteggere le cellule dall'infezione virale.

Abbiamo valutato l'attività antivirale dell'acido cicorico nei confronti di HSV-1 e comparato l'attività in vitro dell'acido cicorico con quella di un estratto acquoso ottenuto dalla cicoria contenente una elevata percentuale di acido cicorico. La tossicità cellulare dell'acido cicorico e dell'estratto dell'acido cicorico è stata determinata mediante riduzione di 3-(4,5dimetiltiazol-2-il)-2,5difenil tetrazolio bromuro (MTT) in monostrati di cellule VERO.

L'attività antivirale nei confronti dell'HSV-1 è stata determinata mediante riduzione del numero di placche in monostrati di cellule VERO.

L'attività antivirale di questi due principi è stata anche studiata mediante riduzione di (2,3-bis[2-metossi-4-nitro-5-sulfofenil]-5-[(fenilamino)carbonil-2H-tetrazolio] (XTT).

I risultati ottenuti indicano che l'acido cicorico presenta una elevata attività neutralizzante verso HSV-1.

Tale attività è meno evidente nell'estratto dell'acido cicorico. Tuttavia quest'ultimo mostra una significativa attività antivirale determinata mediante yield reduction assay dovuta alla presenza di derivati fenolici.

Sia l'estratto che l'acido cicorico puro sono in grado di inibire la diffusione del virus da cellula a cellula come determinato mediante inhibition of plaque development assay.

Queste considerazioni indicano che l'acido cicorico può avere un potenziale impiego clinico nella profilassi delle infezioni sostenute da HSV anche nel paziente immunocompromesso.

L'estratto dell'acido cicorico deve invece essere ulteriormente studiato per un possibile impiego nel trattamento delle infezioni clinicamente evidenti anche per la capacità di inibire la disseminazione delle infezioni erpetiche. 